\title{
INTERDISCIPLINARIDADE EM PROJETOS VOLTADOS À TERCEIRA IDADE ${ }^{1}$
}

\section{IMPACT ANALYSIS OF A HEALTH EDUCATION PROGRAM ON THE LIPID PROFILE OF ELDERLIES}

\author{
Sandra Mara Bragagnolo* \\ Joel Haroldo Baade** \\ Danilo Erhardt*** \\ Maicon Ricardo Deon****
}

\begin{abstract}
Resumo: A sociedade digital constitui-se em desafio para muitas pessoas, especialmente para a terceira idade. A realização de projetos com o objetivo de estimular pessoas desta faixa etária a construírem conhecimentos que lhes permitam inserir-se na sociedade digital é importante e merece análise. A complexidade do desafio, por sua vez, impele a uma abordagem interdisciplinar. Desse modo, o presente estudo analisa a perspectiva interdisciplinar presente na aplicação de dois projetos de extensão em que foram ministradas aulas de inserção a tecnologias para pessoas da terceira idade. Os métodos utilizados foram o exploratório e o analítico-descritivo, apoiados em análise dos resultados de forma quantitativa e qualitativa. Essa análise deu-se a partir da aplicação de questionário on-line. A principal conclusão é a de que os projetos trouxeram benefícios para todos os sujeitos envolvidos: idosos, estudantes, docentes e a própria universidade.
\end{abstract}

Palavras chave: Interdisciplinaridade; Sociedade digital; Terceira idade.

\begin{abstract}
The digital society is a challenge for many people, especially for the elderly. Therefore, developing projects aiming at stimulating people of this age group to gather knowledge that allows them to enter the digital society is important and deserves analysis. The complexity of the challenge requires an interdisciplinary approach. Thus, the present study analyzes the interdisciplinary perspective present in the application of two extension projects in which classes introducing technologies were taught to the elderly. The methods used were exploratory and analytical-descriptive, supported by the analysis of results in a quantitative and qualitative way. This analysis was based on the application of an online questionnaire. The main conclusion is that the projects brought benefits to all the individuals involved: seniors, students, teachers and the university itself.
\end{abstract}

Keywords: Interdisciplinarity; Digital society; Elderly. 


\section{Introdução}

As reflexões aqui apresentadas provêm da aplicação de um estudo que analisou a interdisciplinaridade presente na aplicação de dois projetos de extensão em que foram ministradas aulas de inserção a tecnologias para pessoas da terceira idade. Ambos os projetos foram aplicados no primeiro semestre do ano de 2016 e mantidos pelo Programa de Apoio à Extensão e Cultura - PAEC, de uma Universidade do meio-oeste catarinense: um na cidade de Fraiburgo-SC, com aulas ministradas pelo acadêmico do curso de Administração Maicon Ricardo Deon; e outro em Caçador-SC, ministrado por Danilo Erhardt, também do curso de Administração.

A realização desses projetos teve como foco estimular pessoas da terceira idade a construírem conhecimentos que lhes permitissem inserir-se na sociedade digital. Dessa forma, estiveram entre seus objetivos não somente auxiliar no desenvolvimento de competências sobre a utilização correta de computadores quanto a aspectos de ética e segurança, mas também oportunizar atividades que produzissem estímulos cerebrais importantes para pessoas nessa idade. Com as ações propostas, foi possível promover melhoria na qualidade de vida e na capacidade de interação do público envolvido.

Para que se atingissem esses objetivos, foi necessário o desenvolvimento de uma visão interdisciplinar, tanto nos momentos de produzir conhecimentos quanto na aplicação e socialização destes. A interdisciplinaridade "busca responder à necessidade de superação da visão fragmentada nos processos de produção e socialização do conhecimento" (THIESEN, 2008, p. 546).

A interdisciplinaridade, portanto, diz respeito a ações voltadas para uma aprendizagem que estimule a sistematização dos conhecimentos adquiridos e que se distancie do acúmulo de informações, as quais pouco ou nada contribuem para alterar as relações com a realidade em que se inserem e atuam as pessoas.

\section{Terceira Idade}

Segundo estimativas, "o Brasil tem 20,6 milhões de idosos, número que representa $10,8 \%$ da população total" (PORTAL BRASIL, 2014, web). Há dados que mostram a importância de promover o acesso ao conhecimento para a população idosa: "houve aumento significativo no percentual de idosos alfabetizados do País. [...] esse percentual, em 2002, passou para $64,8 \%$, o que representa um crescimento de $16,1 \%$ em relação a 1991" (BRASIL, 2002).

$\mathrm{O}$ século $\mathrm{XX}$ foi marcado pelo aumento do tempo de vida das pessoas. "A esperança de vida experimentou um incremento de cerca de 30 anos ao longo do século 20, numa profunda revolução da demografia e da saúde pública" (VERAS; CALDAS, 2004 , p. 424). E essa realidade passou a demandar esforços e ações para melhor atender ao crescente contingente de população idosa.

A Organização Mundial da Saúde adotou o termo "envelhecimento ativo" para fazer referência à ideia de que, quando se deseja que o envelhecimento seja uma experiência positiva, deve vir acompanhado de oportunidades em que se privilegiem a saúde, a participação e a segurança (WORLD HEALTH ORGANIZATION, 2005).

O cenário que se desenha é de profundas transformações sociais, não só pelo aumento proporcional do número de idosos nos diferentes países e sociedades, mas igualmente em função do desenvolvimento da ciência e da tecnologia (VERAS; CALDAS, 2002). Para ter saúde mental, pessoas na terceira idade precisam exercitar constantemente seus cérebros para que não percam ou tenham prejudicada sua capacidade de raciocinar e tornem-se ameaçadas por doenças degenerativas. Dessa forma, deve-se primar por disseminar a ideia do envelhecimento ativo, que "é o processo de otimização das oportunidades de saúde, participação e segurança, com o objetivo de melhorar a qualidade de vida à medida que as pessoas ficam mais velhas" (WORLD HEALTH ORGANIZATION, 2005, p. 13).

A capacidade de interagir socialmente e de continuar aprendendo são atividades fundamentais para a população da terceira idade. "As pessoas idosas desejam e podem permanecer ativas e independentes por tanto tempo quanto for possível, se o devido apoio lhes for proporcionado" (VERAS; CALDAS, 2002, p. 429). Desenvolvendo atividades de interação e aprendizagem, essa parcela da população pode conquistar e manter redes de apoio social, além de garantir que seu cérebro se mantenha ativo e, por conseguinte, que sua qualidade de vida esteja assegurada.

\section{Inclusão digital na Terceira Idade}

Fazer menção à era digital é refletir sobre a constante inovação, sobre descobertas significativas e sobre a complexidade própria dos processos de trabalho. A cultura contemporânea tem se modificado em razão das transformações promovidas pelo avanço das tecnologias. Lemos (2010, p. 15) faz uma análise sobre alterações que a sociedade vem apresentando: "A cultura contemporânea, associada às tecnologias digitais (ciberespaço, simulação, tempo real, processos de virtualização, etc.), vai criar uma nova relação entre a técnica e a vida social que chamaremos de cibercultura".

Nessa realidade, ser humano e tecnologia interagem e produzem novidades em termos subjetivos, cognitivos e de trabalho. "Impulsionada 
pelo conhecimento, a era digital está mudando os cenários laborais, os valores da sociedade e o relacionamento humano de forma mais profunda, trazendo uma série de implicações" (KANAN; ARRUDA, 2013, p. 584). A cibercultura "expressa o surgimento de um novo universal, diferente das formas que vieram antes dele no sentido de que ele se constrói sobre a indeterminação de um sentido global qualquer" (LÉVY, 1999, p. 15).

Uma sociedade que se afirma inclusiva precisa considerar, em suas ações, a população idosa, que, quando em idade produtiva, não teve a necessidade de aprender e a desenvolver-se para interagir com as inúmeras possibilidades e exigências da era da cibercultura. "O desenvolvimento tecnológico atual é de ordem tão variada que fica impossível processar-se com a velocidade adequada a esperada sistematização" (FAZENDA, 2001, p. 16).

A exclusão digital ocorre quando, por falta de acesso ao mundo digital, as pessoas têm afetado, diretamente, o direito à cidadania, assim como sua qualidade de vida (BASTOS, 2009). Ressalta-se que a exclusão digital "atinge principalmente o integrante da terceira idade, que, em consequência das limitações impostas pela idade, é afetado diretamente" (BASTOS, 2009, p. 3).

A inclusão digital traz inúmeros benefícios a pessoas idosas, pois potencializa positivamente a autoestima a partir de sua afirmação como indivíduo ativo, disposto a interagir socialmente. E, sobretudo, é facilitadora do exercício da cidadania.

A inclusão digital, em verdade, é uma necessidade, pois não há como, na atualidade, viver sem se atualizar. Nesse sentido, um incluído digitalmente não é apenas aquele que utiliza as linguagens e os recursos tecnológicos para trocar informações, mas também aquele que aproveita esse suporte para melhorar sua condição de vida.

\begin{abstract}
A educação é um dos meios para vencer os desafios impostos aos idosos pela idade e pela sociedade, propiciando-lhes o aprendizado de novos conhecimentos e oportunidades para buscar seu bem-estar físico e emocional (FREIRE, 2000, p. 93).
\end{abstract}

É preciso, nos dias de hoje, perceber todos os sujeitos cognitivamente ativos, mantendo um ciclo comum de aprendizado, não somente no período escolar, nos anos de colegiado, mas também na sua fase adulta e na velhice.

Assim, ações de inclusão digital e apoio a iniciativas para melhorar a qualidade de vida das pessoas devem ser incentivadas e seus resultados devem ser analisados e divulgados. Além disso, a interdisciplinaridade presente em ações dessa ordem também deve ser analisada.

\section{Postura interdisciplinar}

O termo interdisciplinaridade é composto pelo prefixo inter, que significa posição intermediária, interação, reciprocidade; pelo sufixo dade, que atribui a um adjetivo o valor de substantivo, dando-lhe sentido de ação ou resultado de ação, modo de ser; e, no núcleo do termo, encontra-se a palavra disciplina, que se caracteriza como "ordem que convém ao funcionamento duma organização ou ainda um regime de ordem imposta ou livremente consentida" (ASSUMPÇÃO, 2008, p. 23).

Assim, um projeto interdisciplinar tem como objetivo a integração entre as disciplinas e os diferentes saberes das diferentes áreas do conhecimento. Forma alguma de conhecimento é suficiente por si só, há sempre a necessidade de dialogar com outras formas, deixando-se interpenetrar por elas (FAZENDA, 2001).

A interdisciplinaridade se sustenta na leitura da realidade tal como ela é, assumindo suas nuances e singularidades, bem como a diversidade presente. Assim, age como transgressora, abrindo brechas às formas estabelecidas e enraizadas, colocando as certezas no cenário da temporalidade e da dúvida (MIRANDA, 2008).

Fazenda (2008) afirma que interdisciplinaridade é a "atitude de ousadia e busca frente ao conhecimento". Dessa forma, ações de ensino devem levar em consideração os princípios da interdisciplinaridade para que seus resultados possam ser potencializados. "Se a realidade é complexa, ela requer um pensamento abrangente, multidimensional, capaz de compreender a complexidade do real e construir um conhecimento que leve em consideração essa mesma amplitude" (THIESEN, 2008, p. 545).

Conclui-se, assim, que a postura interdisciplinar, que tem aparecido como procedimento metodológico para dar consistência a ações voltadas para o ensino, opõe-se à fragmentação deste, de modo a atingir a totalidade, o unitário. Propostas interdisciplinares apresentam e envolvem os conteúdos trabalhados em um processo que remete à interpenetração nas diversas áreas do conhecimento, de maneira dinâmica e recíproca.

\section{Material e métodos}

Foram analisados resultados de trabalhos desenvolvidos em dois projetos, nos quais se realizaram aulas de inclusão digital para idosos e idosas, com o objetivo de orientar esse público sobre como utilizar computadores e seus recursos, bem como estimular a atividade cerebral e de interação entre essas pessoas.

As aulas de inclusão digital desenvolveram-se em três horas semanais e seguiram etapas que 
respeitaram os objetivos específicos propostos nos projetos de trabalho apresentados e aprovados pelo Programa de Apoio à Pesquisa - PAEC da Universidade Alto Vale do Rio do Peixe - UNIARP. As aulas aconteceram no decorrer do primeiro semestre de 2016, em laboratórios de informática, nas cidades de Caçador e Fraiburgo, ambas no estado de Santa Catarina.

O público-alvo, composto por 30 pessoas com 60 anos ou mais, inscreveu-se livremente para participar dos projetos. O contato foi feito através do Programa Universidade Aberta da Melhor Idade UAMI, em ambas as cidades. Esse público teve a oportunidade de aprender a utilizar computadores e seus recursos sob a orientação dos acadêmicos do curso de Administração de Empresas Danilo Erhardt (em Caçador) e Maicon Ricardo Deon (em Fraiburgo), que desenvolveram seus projetos sob a orientação dos professores Sandra Mara Bragagnolo e Joel Haroldo Baade.

A cada semana, os acadêmicos elaboraram planos de aula e os aplicaram. Após cada aula, fizeram relatórios sobre suas observações e impressões quanto ao progresso de seus alunos e alunas, registrando dificuldades e o que poderia ser melhorado e/ou mantido em suas aulas.

Os métodos utilizados foram o exploratório e o analítico-descritivo, apoiado em análise dos resultados de forma quantitativa e qualitativa. Essa análise deu-se a partir da aplicação de questionário on-line, quando da conclusão do ciclo de aulas, pelos dois acadêmicos, junto aos participantes das aulas de inclusão digital ministradas por eles. Esse questionário foi respondido por 21 sujeitos, em documento on-line. A pesquisa respeitou os preceitos éticos e só foi aplicada após parecer favorável do Comitê de Ética em Pesquisa da Universidade Alto Vale do Rio do Peixe, sob número 051294/2016.

As perguntas elaboradas para compor o questionário solicitavam que a pessoa participante avaliasse as afirmações que compunham o enunciado das questões com variáveis de nota entre 1 e 10 , sendo a nota tão menor quanto menor fosse sua concordância com a afirmação; e tão maior quanto maior sua concordância. Esse formato de resposta levou à coleta de dados sobre a satisfação e o entendimento ou concordância sobre o conteúdo das questões propostas.

Assim, foi possível coletar dados para analisar os resultados das atividades desenvolvidas, bem como diagnosticar a presença da interdisciplinaridade nos trabalhos e ações desenvolvidas, as quais deveriam apontar para a aquisição de competências das pessoas da terceira idade quanto à inserção ao mundo digital.

\section{Resultados}

Segundo o estatuto do idoso, no Brasil, são consideradas idosas as pessoas com idade igual ou superior a 60 anos (BRASIL, 2007). Após conclusão da coleta de dados, verificou-se que a média de idade do público-alvo é de 65,4 anos. Esse público, portanto, insere-se na parcela da população em terceira idade da região de Caçador e Fraiburgo.

Os acadêmicos conduziram as aulas de inclusão digital a partir da associação de aulas expositivas (em que explicavam os conteúdos) com atividades práticas (em que se aplicavam e se sistematizavam, imediatamente, o que se trabalhava). Os participantes das aulas avaliaram esse método de forma positiva, atribuindo notas entre 8 e 10, predominando a nota 10 , com $52,4 \%$ das respostas, atestando a importância da contextualização dos conteúdos.

Em uma prática interdisciplinar, é preciso que os conteúdos estejam vinculados à realidade de quem precisa e quer aprender. "Nesse sentido, precisa ser um projeto que não se oriente apenas para o produzir, mas que surja espontaneamente, no suceder diário da vida, de um ato de vontade" (FAZENDA, 2001, p. 17). Quanto aos conteúdos trabalhados, conforme se pode observar no Gráfico 1, o público demonstrou-se satisfeito.

Gráfico 1 - Nível de satisfação dos participantes com relação aos conteúdos aprendidos

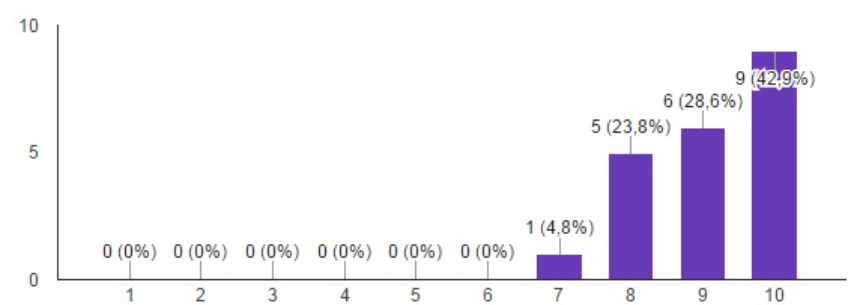

Fonte: Dados da pesquisa.

"Ao homem cabe o prazer de buscar o inesgotável [...], encontrar um equilíbrio interior que lhe permita conviver com a dúvida e a caminhar na incerteza" (FERREIRA, 2001, p. 22). Atividades que se realizam em grupo proporcionam, além do crescimento cognitivo, o estreitamento de relações humanas. Isso porque, em um grupo que se reúne para aprender, as pessoas precisam demonstrar suas dúvidas e inseguranças, revelando fragilidades. Por isso, solicitou-se aos participantes que avaliassem o quanto participar das aulas contribuiu para o fortalecimento de laços de amizade entre eles. Os níveis de avaliação variaram entre os níveis 7 e 10, predominando a nota 10 , com $61,9 \%$ das respostas.

Ainda em se tratando das relações proporcionadas pelo desenvolvimento de habilidades a partir do conhecimento, os participantes foram solicitados a avaliar em que nível puderam ajudar outras pessoas com o que aprenderam. Como se pode observar no Gráfico 2, houve bastante divisão entre as respostas. Entretanto, cabe ressaltar que não houve, 
absolutamente, resposta nula para essa avaliação, ou seja, todos, de alguma forma, contribuíram para melhorar seu entorno a partir do que aprenderam. Essa é uma característica da interdisciplinaridade, visar à construção de um saber não fragmentado, que possibilita a relação com o mundo e consigo mesmo, uma visão de conjunto na transformação de situações com que o indivíduo se defronta em determinados momentos (GADOTTI, 2006).

Gráfico 2 - Nível em que os conhecimentos adquiridos permitiram ajudar a outras pessoas

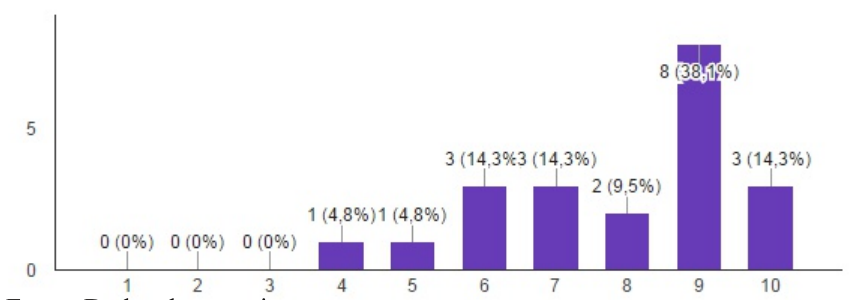

Fonte: Dados da pesquisa.

Aprende-se, com a interdisciplinaridade, que um fato ou solução nunca é isolado, mas sim consequência da relação entre muitos outros (FERREIRA, 2001). Os participantes avaliaram as mudanças em sua vida após terem acesso aos conteúdos ministrados nas aulas. Nesse quesito, atribuíram as variáveis 9 e 10 para as mudanças positivas que perceberam em sua vida cotidiana.

Em um projeto interdisciplinar, nas palavras de Ivani Fazenda (2001), "não se ensina, nem se aprende: vive-se, exerce-se" (FAZENDA, 2001, p. 17). Ao avaliar em que nível os conhecimentos adquiridos estão relacionados a suas atividades diárias, os participantes demonstraram, através de sua avaliação, que percebem a aplicação do que aprendem, conforme se pode visualizar no Gráfico 3.

Gráfico 3 - Avaliação da aplicação dos conhecimentos adquiridos

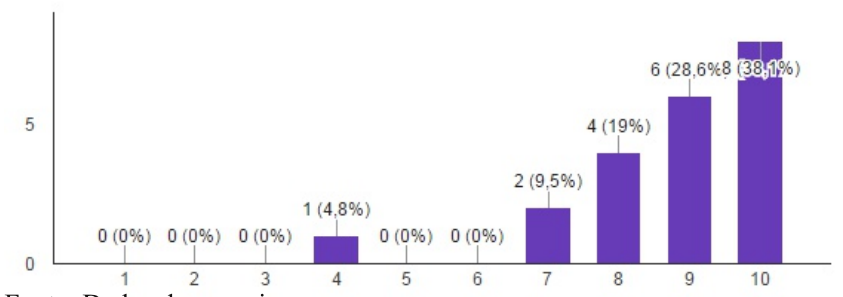

Fonte: Dados da pesquisa.

Avaliou-se o que o público-alvo pensa sobre a formação do conhecimento. $\mathrm{Na}$ perspectiva interdisciplinar, há um esforço para integrar os saberes, desfragmentando-os, "ser interdisciplinar é saber que o universo é um todo, que dele fazemos parte como fazem parte do oceano as suas ondas" (FERREIRA, 2001, p. 20). A interdisciplinaridade, como um enfoque teórico-metodológico, visa superar

[...] a fragmentação e o caráter de especialização do conhecimento, causados por uma epistemologia de tendência positivista em cujas raízes estão o empirismo, o naturalismo e $\mathrm{o}$ mecanicismo científico do início da modernidade (THIESEN, 2008, p. 547).
Como se pode observar no Gráfico 4, as respostas obtidas apontaram para a redução desse equívoco que se enraíza nas concepções do senso comum, haja vista os indícios de que há o entendimento de que o conhecimento é um só, sem divisões.

Gráfico 4 - Concordância com a afirmação de que o conhecimento é um só, sem divisões

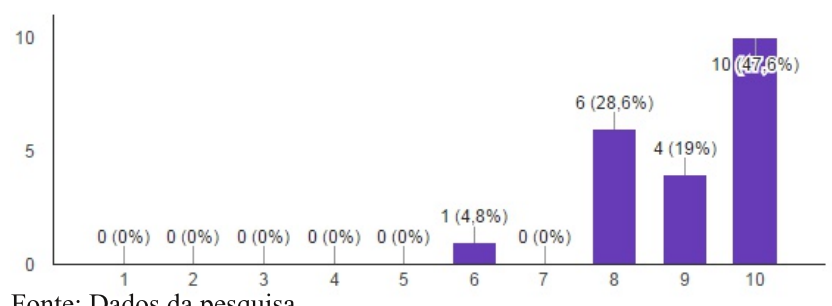

Fonte: Dados da pesquisa.

O Gráfico 5 mostra o nível em que os participantes usaram (ou usam) tecnologias da informação em seu trabalho. Houve bastante divisão entre as avaliações para essa afirmação, demonstrando a heterogeneidade da realidade dessas pessoas. Percebe-se, pelas respostas obtidas, que há pessoas que avaliaram que pelo fato de haverem saído do mercado de trabalho em uma época em que as tecnologias não faziam parte do universo laboral não tiveram a necessidade de desenvolverem habilidades e competências para lidar com os recursos e exigências do mundo digital. E há também os que, sim, utilizaram ou utilizam tecnologias digitais em seus trabalhos. Mesmo assim, aderiram à proposta de frequentar um curso de inclusão digital.

Gráfico 5 - Nível em que os participantes usaram (ou usam) tecnologias em suas atividades laborais

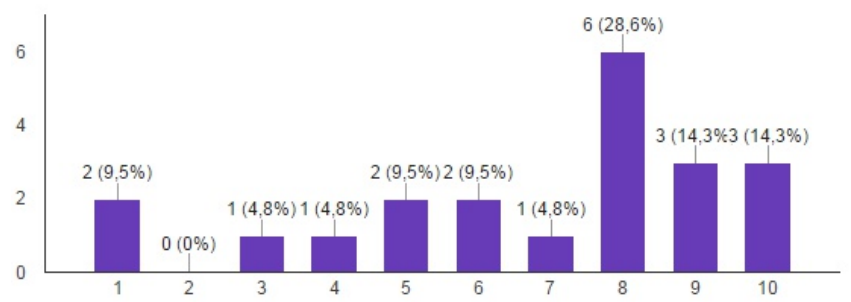

Fonte: Dados da pesquisa

A aprendizagem significativa está associada à mudança de atitudes em relação à realidade que cerca os indivíduos que buscam aprender. "Um projeto interdisciplinar de trabalho ou de ensino consegue captar a profundidade das relações conscientes entre pessoas e entre pessoas e coisas" (FAZENDA, 2001, p. 17). Os participantes das aulas de inclusão digital foram solicitados a avaliar o nível em que o que aprenderam gerou novas atitudes. As respostas concentraram-se entre os níveis 7 e 10. Dessa forma, pode-se concluir que se conseguiu cumprir o objetivo de ensinar algo que tenha sentido empírico, aplicável à realidade e que contribua para o crescimento individual e coletivo.

Este é um traço importante da interdisciplinaridade, caracterizar-se pelo grau de integração real das disciplinas, exigindo que, em seu processo constante e desejável de interpenetração, se fecundem cada vez mais reciprocamente (JAPIASSU, 
1976 apud THIESSEN, 2008). Sabendo também que o que caracteriza a atitude interdisciplinar é "a ousadia da busca, da pesquisa: é a transformação da insegurança num exercício do pensar, do construir" (FAZENDA, 2001, p. 18), o público-alvo da pesquisa avaliou o nível em que, a partir do que aprenderam nas aulas de inclusão digital, puderam desenvolver outros conhecimentos.

O Gráfico 6 mostra que todas as respostas se concentraram na segunda parte do gráfico, ou seja, houve a percepção, por parte da maioria, de que o que se aprendeu levou, consequentemente, à aplicação e ao desenvolvimento de novos conhecimentos e atitudes. Não há como permanecer igual depois de desenvolver o domínio de algo que, efetivamente, se aprende. Miranda (2001, p. 113) afirma que a interdisciplinaridade é "integradora e relacionadora de diferentes áreas do conhecimento". Aprende-se com a interdisciplinaridade que um fato ou solução nunca é isolado, mas consequência da relação entre muitos outros (FERREIRA, 2001). A mudança de atitude em relação ao mundo é consequência imanente ao processo de entendimento da realidade.

Gráfico 6 - Nível em que os conteúdos aprendidos levaram a novas atitudes

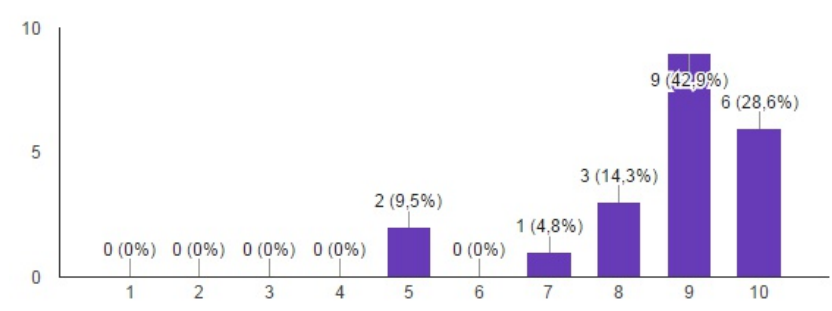

Fonte: Dados da pesquisa.

Ao responderem sobre o nível em que as aulas trouxeram segurança para desenvolver suas potencialidades, novamente houve concentração de respostas entre os níveis 7 e 10, predominando respostas entre 9 e 10 (14 dos 21 indivíduos). Essa constatação revela o quanto o conhecimento altera a qualidade de vida e promove o exercício da cidadania.

Alguém que sabe utilizar dos recursos disponíveis, no caso, tecnologias de acesso à informação e interação, adquire segurança e autonomia na resolução de suas dúvidas, bem como em suas atitudes para resolver suas contingências através das tecnologias. Dominar esse saber evita desgastes para esse público que precisa de serenidade e cuidados para com sua saúde e integridade física e mental. Além disso, afasta o idoso ou idosa da dependência de outras pessoas, o que, durante muito tempo, e ainda nos dias de hoje, foi próprio dessas pessoas, que se tornam extremamente dependentes de pessoas mais jovens, justamente por não saberem lidar com o ambiente virtual.

A busca pelo conhecimento tem várias razões, entre elas, a de inclusão, de não rejeição por não entender e aplicar um saber. Perguntou-se aos participantes em que nível já se sentiram discriminados por não terem o domínio de conhecimentos relacionados à tecnologia da informação. As respostas, vistas no Gráfico 7, permitem concluir que todos, em maior ou menor grau, já vivenciaram o sentimento de exclusão por falta de conhecimento.

Gráfico 7 - Nível em que houve o sentimento de discriminação por falta de conhecimento de tecnologias

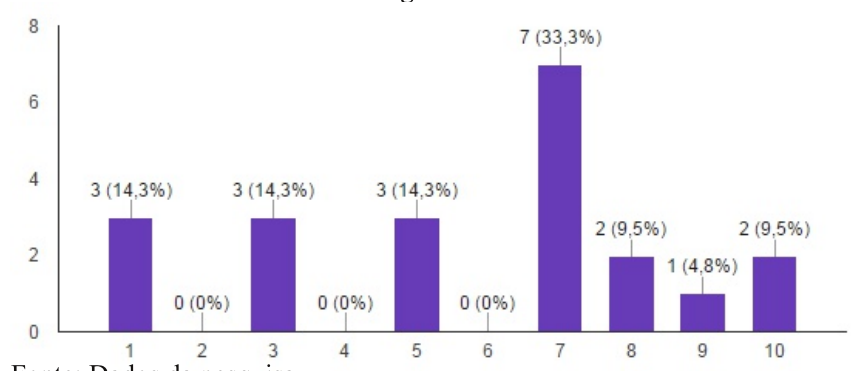

Fonte: Dados da pesquisa.

Uma iniciativa como a desenvolvida na aplicação desses projetos permitiu aos idosos perceberem seu potencial mental e, por extensão, participarem da sociedade de acordo com suas necessidades e capacidades, agregando valor positivo à sua qualidade de vida. Dessa forma, percebe-se que uma postura interdisciplinar leva a aprender com a percepção da amplitude de influência que o conhecimento proporciona.

\section{Considerações finais}

A aplicação deste estudo possibilitou avaliar a interdisciplinaridade presente nas ações e os resultados que trabalhos de inclusão digital proporcionaram a grupos de idosos de Caçador e de Fraiburgo. Esses trabalhos estiveram voltados a melhorar a qualidade de vida do público-alvo, dando-lhe possibilidade de conectar-se e interagir através das Tecnologias da Informação.

Os resultados da pesquisa conduziram para importantes conclusões, que podem nortear ações institucionais voltadas à população da terceira idade, a qual tem aumentado e faz com que a atenção a questões a ela relacionadas seja de relevância para a sociedade como um todo.

Com o aumento progressivo do contingente de idosos, trabalhos como o apresentado aqui, desenvolvido por iniciativa originada no meio acadêmico, demonstra, a partir dos resultados alcançados, a importância de as universidades participarem do desenvolvimento de políticas que protejam e estimulem a qualidade de vida dessa parcela da população.

As universidades, particularmente, podem oferecer atividades financiadas por programas de pesquisa, como campo de experimentação e assistência voltado para os desafios da terceira idade. Como se depreende a partir da aplicação dos projetos analisados, as pessoas diretamente beneficiadas ainda 
representam uma parcela pequena dos usuários potenciais. Por isso, é preciso que esse tipo de ações, que primam pelo desenvolvimento integral das pessoas, seja estimulado, e, ainda, que práticas interdisciplinares de atendimento aos idosos se multipliquem e gerem conhecimento e saberes que promovam o exercício da cidadania ao maior número possível deles.

Para os estudantes envolvidos, a oportunidade de crescimento e o estímulo de suas competências foram fundamentais. A partir das atividades que desenvolveram, tiveram oportunizada a reorganização de seus saberes para que pudessem produzir conhecimento nos sujeitos que os acompanharam, em um processo de construção e troca de experiências cognitivas enriquecedoras.

\section{Referências}

ASSUMPÇÃO, Ismael. Interdisciplinaridade: uma tentativa de compreensão do fenômeno. In: FAZENDA, Ivani Catarina Arantes (Coord.). Práticas interdisciplinares na escola. 8.ed. São Paulo: Cortez, 2001.

BASTOS, Vera Regina dos Santos. Inclusão digital da terceira idade. Disponível em:

$<$ http://guaiba.ulbra.br/seminario/eventos/2009/artigos/siste mas/salao/524.pdf>. Acesso em: 14 fev. 2016.

\section{BRASIL. IBGE. Perfil dos idosos responsáveis pelos}

domicílios. Disponível em:

$<$ http://www.ibge.gov.br/home/presidencia/noticias/250720

02pidoso.shtm>. Acesso em: 12 jul. 2016.

BRASIL. MINISTÉRIO DA SAÚDE. Estatuto do Idoso.

2.ed. Brasília: Ministério da Saúde, 2007.

CALDAS, Célia Pereira; VERAS, Renato Peixoto. Promovendo a saúde e a cidadania do idoso: o movimento das universidades da terceira idade. Revista Ciência \&

Saúde Coletiva, v. 9, n. 2, 2004. Disponível em:

$<$ http://www.scielo.br/pdf/\%0D/csc/v9n2/20396.pdf>. Acesso em: 14 jul. 2016.

FAZENDA, Ivani Catarina Arantes (Org.). O que é interdisciplinaridade? São Paulo: Cortez, 2008.

Interdisciplinaridade: definição, projeto, pesquisa. In: FAZENDA, Ivani Catarina Arantes (Coord.). Práticas interdisciplinares na escola. 8.ed. São Paulo: Cortez, 2001.

FERREIRA, Maria Elisa de M. P. Ciência e interdisciplinaridade. In: FAZENDA, Ivani Catarina Arantes (Coord.). Práticas interdisciplinares na escola. 8.ed. São Paulo: Cortez, 2001.

FREIRE, Sueli Aparecida; SOMMERHALDER, Cinara. Envelhecer nos tempos modernos. In: FREIRE, Sueli Aparecida; NERI, Ana Liberalesso (Orgs.). E por falar em velhice. Campinas: Papirus, 2000.

GADOTTI, Moacir. Interdisciplinaridade: atitude e método. São Paulo: Instituto Paulo Freire, 2006. Disponível em: <www.paulofreire.org>. Acesso em: 12 jul. 2016.

KANAN, Lilia Aparecida; ARRUDA, Marina Patrício de. A organizacão do trabalho na era digital. Revista Estudos de Psicologia, Campinas, v. 30, n. 4, out./dez. 2013.

Disponível em:

$<$ http://www.scielo.br/pdf/estpsi/v30n4/11.pdf>. Acesso em: 13 jul. 2016.
LEMOS, André. Cibercultura: tecnologia e vida social na cultura contemporânea. 5.ed. Porto Alegre: Sulina, 2010.

LÉVY, Pierre. Cibercultura. São Paulo: Editora 34, 1999.

MIRANDA, Raquel Gianolla. Da interdisciplinaridade. In: FAZENDA, Ivani (Org.) O que é interdisciplinaridade? São Paulo: Cortez, 2008.

PORTAL BRASIL. Brasil é reconhecido por políticas públicas em favor de idosos. Disponível em:

$<$ http://www.brasil.gov.br/saude/2014/01/brasil-ereconhecido-por-politicas-publicas-em-favor-de-idosos $>$. Acesso em: 30 abr. 2016.

THIESEN, Juares da Silva. A interdisciplinaridade como um movimento articulador no processo ensino-aprendizagem.

Revista Brasileira de Educação, v.13, n. 39, set./dez. 2008.

WORLD HEALTH ORGANIZATION. Envelhecimento ativo: uma política de saúde. Brasília: Organização PanAmericana da Saúde, 2005.

XAVIER, V.F.; DINIZ, W.Y. Qualidade de vida na terceira idade: estudo exploratório na população de duas instituicões geriátricas do norte do Paraná. Disponível em: $<$ http://fio.edu.br/cic/anais/2009_viii_cic/Artigos/07/07.11.p df> Acesso em: 09 jul. 2016.

Notas:

${ }^{1}$ Os autores estão vinculados ao projeto do XV ENCONTRO ESTADUAL DO PROLER DE CAÇADOR E WORKSHOP DAS LICENCIATURAS, que contou com apoio financeiro da Chamada Pública FAPESC No 07/2016 - PROEVENTOS-2017-2018/FASE 1 . 